\title{
Dimensões da construção e execução do projeto político pedagógico: um estudo de caso
}

\author{
Dimensions of the construction and implementation of pedagogical \\ political project: a case study
}

\author{
Hamilton Matos Cardoso Júnior* \\ Universidade Estadual de Goiás \\ Priscilla Fabiane de Brito** \\ Universidade Estadual de Goiás \\ Divina Aparecida Leonel Lunas*** \\ Universidade Estadual de Goiás
}

Thiago Weslei de Almeida Sousa**** Universidade Estadual de Goiás

Resumo O Projeto Politico Pedagógico (PPP) é uma importante ferramenta, articulada a outras, para a construção da educação de qualidade. Deve englobar a comunidade, os alunos e o corpo de funcionários da escola. Este artigo apresenta resultados de uma pesquisa realizada em uma escola pública da cidade de Anápolis - Goiás. Seu objetivo é evidenciar como o PPP foi construído e aplicado na prática escolar da instituição. Para a realização deste trabalho, procedeu-se a alguns passos metodológicos, dentre eles: pesquisa bibliográfica; elaboração e aplicação de instrumentos de pesquisa e realização de trabalho de campo. Concluise com este estudo que a construção e execução do PPP enfrentam diferentes dificuldades, dentre elas: os prazos estabelecidos pelo Estado para sua elaboração e a dificuldade em despertar o interesse da comunidade escolar para a participação coletiva.

PALAVRAS-CHAVE: Anápolis; Autogoverno; Documento; Elaboração.

Abstract The Pedagogical Political Project (PPP) is an important tool, articulated the other, for the construction of quality education. Must include the community, students and staff of the school. This article presents the results of a survey conducted in a public school in the city of Anápolis - Goiás. Its goal is to highlight how the PPP was constructed and applied in school practice of the institution. To carry out this work has some methodological steps, among them: bibliographical research; development and implementation of research instruments and performing field work. This study concluded that the construction and implementation of PPP facing various difficulties, including: the deadlines set by the State for its preparation and the difficulty in awakening the interest of the school community for collective participation.

KEYWORDS: Annapolis; Self-government; Document; Preparation. 


\section{Introdução}

A educação encontra-se na confluência do social, do econômico e do cultural. Por esses motivos exige das instituições escolares e, principalmente, de seus profissionais múltiplas habilidades para tarefa de formar não apenas indivíduos particulares, mas indivíduos coletivos e dotados de senso crítico do mundo a sua volta.

O referido artigo busca, baseando-se em autores da educação, exemplificar as bases em que o PPP (Projeto Político Pedagógico) deve ser ancorado para sua construção e implantação. Essas bases devem constituir-se, antes de tudo, na gestão democrática escolar, buscando proporcionar a autonomia da instituição.

Buscando entender/conhecer a realidade da construção deste documento, é apresentado um relato de pesquisa do processo de elaboração e execução do PPP de uma escola localizada na cidade de Anápolis - Goiás. Sobre este relato, busca-se mostrar a realidade desta ferramenta da educação. Entretanto, ressalta-se que os problemas identificados não pertencem somente à escola pesquisada, mas que se constitui como fato de diversas instituições escolares de nosso país, resultado do sistema imposto às instituições escolares brasileiras.

Para o desenvolvimento da pesquisa foram utilizados alguns passos metodológicos: pesquisa bibliográfica com referência ao assunto, análise do PPP da instituição e pesquisa de campo utilizando entrevistas (a representantes da instituição) e questionários (aos alunos de uma turma específica da escola).

O intuito do questionário é conhecer a realidade social desses grupos e identificar sua participação na construção do referido documento. Também foram avaliadas a necessidade e a importância atribuída pelos entrevistados à presença de uma abordagem multicultural no PPP, os problemas burocráticos, como os prazos exíguos para a produção do documento, e a dificuldade em garantir a participação da comunidade escolar no processo de construção dessa ferramenta.

Este artigo divide-se em cinco seções, a contar com esta introdução. Portanto, a segunda seção apresenta os princípios constitutivos do PPP obtidos em diferentes referências bibliográficas e na legislação; a terceira parte busca evidenciar a noção regulatória e emancipatória dessa ferramenta; a quarta seção apresenta os resultados obtidos com o trabalho de campo e análise do PPP da escola pesquisada; e, por fim, na quinta seção destacamos nossas considerações finais.

\section{O projeto político pedagógico e seus princípios construtivos}

O Projeto Político Pedagógico é um documento escolar que possui suma importância no desenvolvimento da educação de cada instituição de ensino. Todavia, a forma como tem sido introduzido no meio escolar, não levando em conta as regras/ métodos eficazes, tem feito com que este documento não atinja seu objetivo principal, qual seja: antecipar e orientar as ações a serem desenvolvidas na escola. Veiga (1995) nos elucida que: 
O projeto busca um rumo, uma direção. É uma ação intencional, com um sentido explícito, com um compromisso definido coletivamente. Por isso, todo projeto pedagógico da escola é, também, um projeto político por estar intimamente articulado ao compromisso sociopolítico com os interesses reais e coletivos da população majoritária. É político no sentido de compromisso com a formação do cidadão para um tipo de sociedade. [...] Pedagógico, no sentido de definir as ações educativas e as características necessárias às escolas de cumprirem seus propósitos e sua intencionalidade. (VEIGA, 1995, p. 13).

Vasconcellos (1995) ainda acrescenta que:

Projeto Pedagógico [...] é um instrumento teórico-metodológico que visa ajudar a enfrentar os desafios do cotidiano da escola, só que de uma forma refletida, consciente, sistematizada, orgânica e, o que é essencial, participativa. É uma metodologia de trabalho que possibilita re-significar a ação de todos os agentes da instituição (VASCONCELLOS, 1995, p.143).

No Brasil, a educação deve ser ministrada com base nos princípios, dentre outros, de igualdade, liberdade de aprender, respeito à pluralidade de ideias, gestão democrática do ensino público e valorização das experiências extraescolares, objetivos trazidos pela Lei de Diretrizes e Bases da Educação de 1996 (BRASIL, 1996). Ainda segundo referido dispositivo legal, cada instituição terá como responsabilidade a elaboração de sua prática pedagógica.

Aliado a isso, Cavalcanti (2008) afirma que "o contexto atual é, na verdade, o de uma nova cultura - um novo espaço, uma nova espacialidade -, que é bastante complexa e que requer análises amplas" (CAVALCANTI, 2008, p. 41). Ainda segundo a autora, o mundo atual constitui-se como globalizado, porém, não homogeneizado. Pelo contrário, vivemos em um mundo globalizado onde participam diversos países, porém, nem todos da mesma forma. Uma globalização que fragmenta e cria diferenças espaciais, que resultam em alterações na rotina escolar, realidade que deve ser englobada no PPP.

O artigo 14, incisos I e II da Lei de Diretrizes e Bases da Educação (BRASIL, 1996), afirma que:

Art. $14^{\circ}$. Os sistemas de ensino definirão as normas da gestão democrática do ensino público na educação básica, de acordo com suas peculiaridades e conforme os seguintes princípios:

I - participação dos profissionais da educação na elaboração do projeto pedagógico da escola;

II - participação das comunidades escolar e local em conselhos escolares ou equivalentes. (BRASIL, 1996)

Dessa forma, é de responsabilidade da instituição escolar elaborar sua proposta pedagógica, seu PPP. Entretanto, segundo Romão (1997) e a referida lei, essas instituições deverão assegurar a participação de seus profissionais da educação e de sua comunidade escolar local na elaboração e implantação de seu PPP, não ficando 
essa tarefa, assim, restrita apenas ao seio técnico-administrativo. Dessa maneira a instituição estará assegurando a gestão democrática e a participação de todos os sujeitos envolvidos no processo de construção da educação de qualidade.

A respeito do assunto, Araújo (2000) nos afirma que:

[...] a transparência afirma a dimensão política da escola, sua existência pressupõe a construção de um espaço público vigoroso e aberto à diversidade de opiniões e concepções de mundo, contemplando a participação de todos os que estão envolvidos com a escola. (ARAÚJO, 2000, p. 155)

Marques (1990) ainda sustenta que:

A participação ampla assegura a transparência das decisões, fortalece as pressões para que elas sejam legítimas, garante o controle sobre os acordos estabelecidos e, sobretudo, contribui para que sejam contempladas questões que de outra forma não entrariam em cogitação. (MARQUES, 1990, p. 21).

Dessa forma, podemos afirmar que o PPP, dentre outras ações, compreende a afirmação de uma gestão democrática dentro da escola, a qual a LDB (BRASIL, 1996) assegura em suas linhas. Segundo Dourado e Duarte (2001), a gestão democrática configura-se em:

- Descentralização: a administração, as decisões e as ações devem ser elaboradas, tomadas e executadas de forma não hierarquizada;

- Participação: todos os envolvidos no dia a dia escolar devem participar da gestão, ou seja, professores, estudantes, funcionários, pais ou responsáveis, pessoas que participam de projetos escolares e toda a comunidade ao redor da escola;

- Transparência: qualquer decisão e ação tomada/decidida ou implantada na escola deverá ser de conhecimento de todos.

Ainda segundo a LDB, em seu artigo 15, os sistemas de ensino deverão garantir às unidades escolares públicas autonomia administrativa, pedagógica e financeira (BRASIL,1996). No entanto esse dispositivo não passa de uma utopia representada em letras de uma lei nacional. Na realidade, a autonomia escolar não é respeitada pelo sistema educacional público, visto que as unidades escolares são cada vez mais uniformizadas pedagogicamente e burocraticamente pelas secretarias de educação espalhadas pelo país.

É importante salientar que o sistema educacional deve lançar suas normas gerais sobre as instituições escolares. Entretanto, uniformizar as práticas pedagógicas é um ato diferente. Essas normas devem funcionar como uma bússola que norteia o ensino escolar e não como um sistema homogeneizador de práticas educacionais.

Dessa forma, no sistema atual, apenas se está indo na contra mão da gestão democrática. Ora, se a própria lei assegura que as instituições de educação devem seguir o caminho da gestão democrática, como estas o farão se não são tratadas nos mesmos preceitos? 
Nas palavras de Gadotti (1997), ao se elaborar o projeto político pedagógico de uma escola, estamos planejando e dando intenção ao que se deve fazer/realizar. É nesse documento que serão inseridos os objetivos da escola, seus aspectos históricos, problemas ${ }^{1}$, suas possíveis soluções, além de contribuições para a comunidade em que a instituição possui relações.

Gracindo (2004) aponta o PPP como um instrumento eficaz na construção da educação que se deseja. Segundo a autora, é ele que delineará a escolha e o tipo de educação que se quer construir. O PPP será o documento formal que apontará que tipo de educação que a instituição quer oferecer à sociedade e, consequentemente, que tipos de cidadãos procura formar. No entanto, esta ferramenta não pode ser vista apenas como um documento indiferente, pelas vias tecnicista e meramente formais, o que é comumente realizado nos dias de hoje.

O PPP deve ser um documento que traga autonomia para a instituição escolar ligada à ideia de autogoverno; deverá trazê-la pautada no processo histórico, na multiculturalidade da sociedade e na a gestão democrática da escola. Sobre essa autonomia é que a instituição escolar deve formar seus cidadãos, como nos aponta Araújo (2000).

\section{O projeto político pedagógico e a sua noção de inovação regulatória e emancipatória}

Os dicionários de língua portuguesa trazem o significado de inovação como sendo o ato de introduzir novidades, criar, inventar e renovar. No entanto, quando trazemos a inovação para as políticas públicas, devemos encará-la como sendo uma inovação regulatória ou emancipatória, como faz Veiga (2003) em sua análise sobre estas duas esteiras usadas na construção do PPP. Segundo a referida autora:

O projeto político pedagógico, na esteira da inovação regulatória ou técnica, está voltado para a burocratização da instituição educativa, transformando em mera cumpridora de normas técnicas e de mecanismos de regulação convergentes e dominadores. (VEIGA, 2003, p. 272).

Então, quando construímos e implantamos o PPP de modo/forma regulatória apenas estamos "abrindo as portas" da instituição para unificação de práticas pedagógicas. O PPP, se construído nos moldes regulatórios, se comporá em um documento burocrático e técnico. A instituição, nos moldes técnicos, passa a ser analisada apenas por seus resultados técnicos e por seus indicadores de desempenho. Entretanto, esses resultados não resultam na formação de cidadãos críticos, mas em metas e números a serem alcançados.

Para Veiga (2003), os processos continuam sendo ferramentas inovadoras ferramentas para instituir-se o domínio regulador cada vez maior sobre as instituições escolares. A uniformidade, o planejamento educacional centralizado e o controle burocrático são os resultados da inovação técnica. 
Como vimos anteriormente, o PPP deve ser construído em uma ação coletiva, o que é previsto em lei. No entanto, a construção do PPP sobre as bases da inovação regulatória exclui os sujeitos do processo, descontextualiza a realidade da instituição, da educação e dos tributários que desse processo participam.

Essa inovação passa a acontecer de fora para dentro, é instituída. Indo ao contrário da proposta do PPP como ferramenta para a construção de uma educação de qualidade, que diz que as inovações devem ser discutidas pelos seus sujeitos participantes, ou seja, a mudança deve ocorrer de dentro para fora.

Como aponta Veiga (2003), a inovação técnica regulatória é uma simples rearticulação do sistema que visa a introdução acrítica do novo no velho. Essa inovação apenas será ferramenta para a perpetuação do que já foi instituído. Nesse sentido, o único resultado que o PPP poderá assumir é a sua transformação num documento pronto e acabado, reafirmando a padronização, a uniformidade e o controle burocrático do sistema sobre a educação. Se podemos assim dizer, "engaiolando" as práticas pedagógicas.

Infelizmente, a inovação regulatória é o modelo comumente utilizado na construção e aplicação do PPP nas instituições educacionais brasileiras, sendo este ato reflexo do sistema imposto sobre nossas escolas. Compreender as inovações técnicas na educação básica do sistema brasileiro constitui-se em uma ferramenta importante para criticar e barrar o fenômeno da homogeneização.

Partindo para a análise construtiva do PPP sobre os moldes da inovação emancipatória, Veiga (2003, p. 274) afirma que "a inovação emancipatória ou edificante não pode ser confundida com evolução, reforma, invenção ou mudança”.

Portanto, para a autora, a construção de um PPP sobre a base da inovação edificante não está relacionada à mudança ou ao inovar, diferente do sentido de inovação técnica. Esta será uma construção humana feita pelo coletivo, e consequentemente possuirá maior diálogo com os saberes locais e com suas necessidades. Assim, não ocorrerão mudanças, mas sim aprimoramento do que já foi instituído. Dessa forma, proporcionará uma emancipação concreta da instituição.

A inovação emancipatória deverá propor uma ruptura buscando levar seus sujeitos participantes a uma indagação do sistema colocado, utilizando-se para isso da construção coletiva. Esta se edifica sobre a natureza ético-social e cognitivo-instrumental visando à eficácia dos processos formativos e a uma reprodução crítica (VEIGA, 2003).

A construção do PPP, sobre a perspectiva da inovação emancipatória, permite a instituição repensar sua estrutura de poder e suas relações sociais. A escola não é apenas um local de perpetuação dos valores sociais dominantes, mas um local de combate e de resistência a esses valores.

Sobre a perspectiva dessa construção, a escola não estará sucumbida à homogeneização forçada pelo sistema. Ela se tornará autônoma, pois há protagonistas 
em seu processo. Alunos, professores, técnicos administrativos e a comunidade possuirão sua participação na construção da educação que a escola quer proporcionar, há inclusão de todos os sujeitos envolvidos nas relações da instituição escolar.

\section{Investigação da construção do PPP numa instituição escolar pública em Anápolis - Goiás}

Com base nos autores utilizados para o desenvolvimento deste artigo, realizou-se uma pesquisa prática em uma instituição escolar ${ }^{2}$ localizada em uma área considerada periférica da cidade de Anápolis, estado de Goiás. O objetivo dessa pesquisa é entender as dimensões da construção e execução do PPP.

Nesse contexto, a investigação inicia-se com a análise do PPP da referida escola que, em seu Projeto Político Pedagógico, possui um número total de 77 páginas. Dentre todas as suas informações, chega-se à conclusão que se destacam as seguintes: o histórico da instituição, sua missão/objetivo, diagnóstico da situação atual, gestão escolar e integração da instituição com a comunidade.

A referida escola trata-se de uma instituição fundada, na década de 1980, em decorrência das necessidades ensejadas pelo contexto local à época de sua fundação. $\mathrm{O}$ aumento da população da região ${ }^{3}$, ocasionado pelo surgimento dos bairros em seu entorno foi o principal motivo de sua criação. Por tratar-se de um local relativamente distante do centro e desprovido de infraestrutura, principalmente no âmbito educacional, veio a atender a demanda dos moradores dos bairros próximos. Como já visto acima, o PPP não deve desconsiderar os aspectos históricos da escola, regra que não é desobedecida na construção do referido documento analisado.

Sua missão é calcada na educação de qualidade, buscando formar cidadãos críticos e pensantes, capazes de intervir na realidade, também busca valores universais, destacando-se a fé, o respeito, o amor, a perseverança e o companheirismo.

O PPP da instituição traz sua situação atual e apresenta seus problemas físicos e pedagógicos como: ilegalidade do terreno escolar ${ }^{4}$, estrutura física comprometida, falta de espaço para a acomodação de servidores e alunos, falta de estrutura esportiva ${ }^{5}$, de acessibilidade, problemas na formação dos docentes devido à falta de incentivo e baixo rendimento escolar, dentre outros.

Sua estrutura física data do período de sua criação, possuindo em suas dependências apenas o básico. A instituição conta com laboratório de informática, no qual os computadores existem e possuem aproximadamente três anos de uso, mas não podem ser utilizados devido à retirada do técnico em computação que prestava assistência à escola.

A cozinha é um ambiente pequeno e apertado, porém bem organizado e limpo. Nela são preparadas as refeições distribuídas durante o recreio dos três turnos, utilizando produtos cultivados em uma horta nos fundos do colégio além dos alimentos adiquiridos por meio das verbas do estaduais. 
A sala dos professores também é bastante desconfortável e desprovida de privacidade. Possui, assim como o restante da escola, um mobiliário em bom estado de conservação, comprados com verbas que deveriam servir para a reforma do prédio. Devido a esses problemas conclui-se que efetivar os objetivos e a missão da instituição torna-se mais difícil de ser concretizada. A ausência de uma estrutura física e tecnológica ao alcance dos educandos acaba comprometendo o bom andamento das práticas pedagógicas.

Seguindo com a análise, percebe-se que o documento traz conceitos de gestão democrática. Existem pontos em que asseguram a participação de todos os envolvidos no processo educacional, desde os servidores técnicos até a comunidade escolar. No entanto, de acordo com o depoimento da coordenadora do período vespertino, a gestão no referido modelo não ocorre, ficando a cargo da administração da escola a construção e aplicação do PPP. Ainda segundo a coordenadora pedagógica da escola:

O PPP, apesar das boas intenções que carrega em sua essência, possui mais caráter regulador, não deixando espaço para realmente dar autonomia à escola [...]. Apesar de um dos objetivos contidos em nosso PPP ser a autonomia, torna-se quase impossível, porque a escola não possui autonomia pedagógica. $\mathrm{O}$ Estado de Goiás regula firmemente os conteúdos, o currículo e a burocracia tanto dos professores quanto dos administrativos. (ENTREVISTADO A).

A profissional acredita que o próprio Estado ainda encontra-se "perdido" no que se refere à construção e implantação do documento, uma vez que se mostra um tanto quanto tradicionalista em uma prática considerada como moderna. Dessa forma, as práticas desenvolvidas na instituição, não considerando o PPP como uma ferramenta de autogoverno e de inclusão dos sujeitos envolvidos no processo de ensino-aprendizagem, evidenciam a educação tradicional, baseada no positivismo que desconsidera o bem estar e a autonomia do sujeito, mas que contribui para o processo de exclusão a partir do momento em que se propõe uma educação reprodutora das ideologias do Estado e das classes dominantes. É a escola funcionando, mais uma vez, como forma de aparelhamento estatal e cultural.

Quando indagada sobre os projetos educacionais, considerando-se o contexto e os problemas da comunidade, destacados como elementos presentes no texto do PPP, a coordenadora ressaltou que:

Existem muitos projetos educacionais. Eu vou falar do maior que é o PDE (Plano de desenvolvimento da Escola). Dentro do PDE existem vários projetos porque as ações são feitas quase todas em forma de projetos como: quarta-feira multidisciplinar, folclore, conhecendo um novo Estado (que inclui viagens), literatura e noite cultural. [...] Esses projetos se repetem todos os anos, assim como as feiras. Também procuramos trazer para a escola palestras sobre problemas muito comuns na região da nossa escola, como a droga, a gravidez, problemas sexualmente transmissíveis e outros. (ENTREVISTADO A).

Com relação ao processo de construção do PPP, a coordenadora da instituição nos revelou a realidade presente nesse procedimento. Segundo ela: 
[...] o PPP tem sido construído apenas pelo corpo administrativo da escola [...] É muito difícil envolver a comunidade. Os pais pouco se interessam pelas reuniões bimestrais, não viriam à escola para discutir um documento, penso que acreditam ser perca de tempo [...] Envolver a comunidade é muito difícil. (ENTREVISTADO A)

Com exceção dos projetos educacionais que englobam a comunidade, a exemplo da feira, podemos perceber que não são seguidas as "regras" que seriam os eixos norteadores para a construção desse documento. Ou seja, nem todos os que deveriam estar envolvidos no processo participam, existindo e persistindo inúmeros obstáculos que impedem a construção/elaboração e implantação do documento ancorado em seus princípios, como o da gestão democrática.

A falta de participação dos pais na vida escolar dos estudantes, a desvalorização da educação e a forma como as escolas são tratadas pelo Estado, enquanto lócus de acolhimento social que oferecem ensino desinteressante (LIBÂNEO, 2003), levam à desmotivação dos profissionais e a obstáculos para que o documento seja praticado de forma concreta, fazendo com que acabe engavetado.

As barreiras apontadas por Gracindo (2009) que levam a não participação da comunidade na construção/implantação do PPP são: o modo de colonização, que criou uma verdadeira cultura personalista que pode ser facilmente vista nos senso comum da população ao associar o governo a uma única pessoa; o coronelismo onde o poder concentrava-se nas mãos dos latinfundiários e empresários de importância regional; e o populismo.

Destarte, é notável a existência de um distanciamento entre teoria e prática referente à construção e implantação do PPP. Isso é perceptível quando é possível investigar a sua construção e aplicação, pois embora seja de caráter obrigatório, sua elaboração de forma democrática e participativa é um desafio.

O procedimento demonstrou-se burocrático, para fins de cumprimento da legislação vigente. Porém, o que mais interessa - ou seja, a elaboração/aplicação de um documento que contenha propostas de mudanças educacionais para melhorar o processo ensino-aprendizagem, tornando o aluno sujeito de sua própria história e autônomo, que estreita as relações institucionais da escola com a comunidade e que garanta tempos e espaços de discussão coletiva, não ocorre de forma efetiva. Essa é a lógica do sistema liberal ao qual vivemos: não se deve garantir a formaçãode cidadãos pensantes numa sociedade, pois esses podem descobrir intenções e, consequentemente, voltarem-se contra ideologias da classe dominante e do aparelho estatal.

Diante da necessidade de traçar o perfil do aluno atendido pela referida escola, um questionário socioeconômico foi aplicado. Segundo Gil (1999, p.128), o questionário pode ser definido "como a técnica de investigação composta por um número mais ou menos elevado de questões apresentadas por escrito às pessoas, tendo por objetivo o conhecimento de opiniões, crenças, sentimentos, interesses, expectativas, situações vivenciadas etc." 
Consideramos que o uso do questionário em pesquisas educacionais permite a coleta de informações sobre a realidade, possibilitando entender os aspectos quantitativos e qualitativos do objeto de estudo. Gil (1999) destaca os seguintes pontos positivos no uso dessa técnica de investigação.

a) possibilita atingir grande número de pessoas, mesmo que estejam dispersas numa área geográfica muito extensa, já que o questionário pode ser enviado pelo correio; b) implica menores gastos com pessoal, posto que o questionário não exige o treinamento dos pesquisadores; c) garante o anonimato das respostas; d) permite que as pessoas o respondam no momento em que julgarem mais conveniente; e) não expõe os pesquisadores à influência das opiniões e do aspecto pessoal do entrevistado. (GIL, 1999, p. 128-129).

Portanto, esta ferramenta foi selecionada para pesquisa em virtude de sua adequação ao estudo proposto, permitindo uma análise mais ampla da realidade analisada, além de ser um modelo de fácil aplicação, de custos baixos e hábil a permitir a pesquisa de campo em estudos educacionais.

$\mathrm{Na}$ aplicação do questionário foram destacados alguns aspectos referentes aos alunos investigados, como: a faixa etária, a situação financeira, a região da cidade de onde provém, a distância percorrida para que cheguem até a escola e a situação familiar.

O questionário foi aplicado em três salas, sendo todas elas do sétimo ano do ensino fundamental. Os dados coletados permitiram concluir que o espaço escolar não é homogeneizado, mas heterogêneo e diversificado, seja no aspecto social, financeiro ou cultural.

A aplicação do questionário, em especial, possibilitou refletir sobre as condições sócio-históricas de alguns alunos componentes do quadro discente. Esse aspecto foi interessante, visto que é sempre necessário levá-lo em consideração, ao passo que é através dele que as relações de aproximação (ou não) entre alunos, professores e comunidade escolar ocorrem.

Quanto à média ${ }^{6}$ de idade dos alunos (Figura 1), a maioria possui 12 anos (59\%). No entanto, foi possível encontrar um número elevado de alunos com 17 anos (8\%), sendo esses repetentes. Nas salas pesquisadas, os estudantes possuíam residência em dez bairros diferentes, em sua maioria nas proximidades do bairro onde localiza-se a escola analisada. 
Figura 1: Gráfico - Faixa etária das séries analisadas, $7^{\circ}$ ano

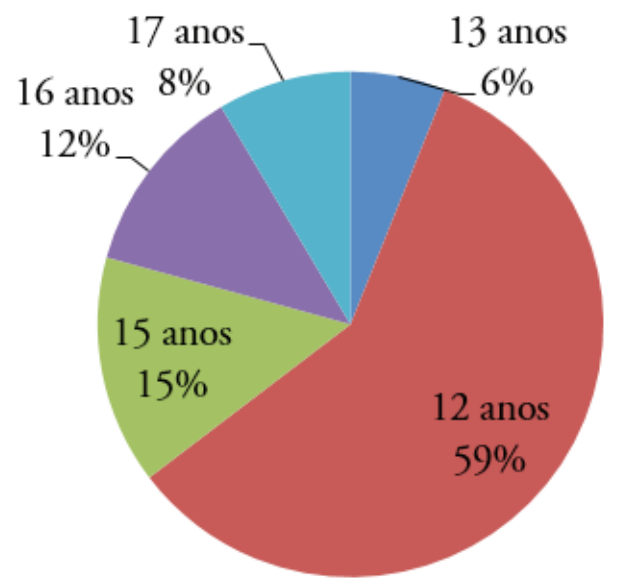

Fonte: Elaborado pelos autores

Quanto à renda familiar dos alunos (Figura 2), 56\% responderam que possuem renda de um a dois salários mínimos, e apenas $8 \%$ responderam que sua família possui renda acima de cinco salários mínimos, o que permite inferir que o público atendido por essa escola é mais carente do ponto de vista fianceiro. Quanto ao fato de uso de transporte público, $40 \%$ dos alunos utilizam transporte coletivo para se deslocar até a escola. $\mathrm{E}$ do total dos estudantes questionados, $81 \%$ deles não trabalham, ao passo que $19 \%$ possuem algum vínculo empregatício. Quanto à naturalidade, $75 \%$ dos alunos são naturais do município de Anápolis, $13 \%$ de cidades de outros municípios goianos e $12 \%$ de outros estados do país.

Figura 2: Gráfico - Renda média das séries analisadas, $7^{\circ}$ ano

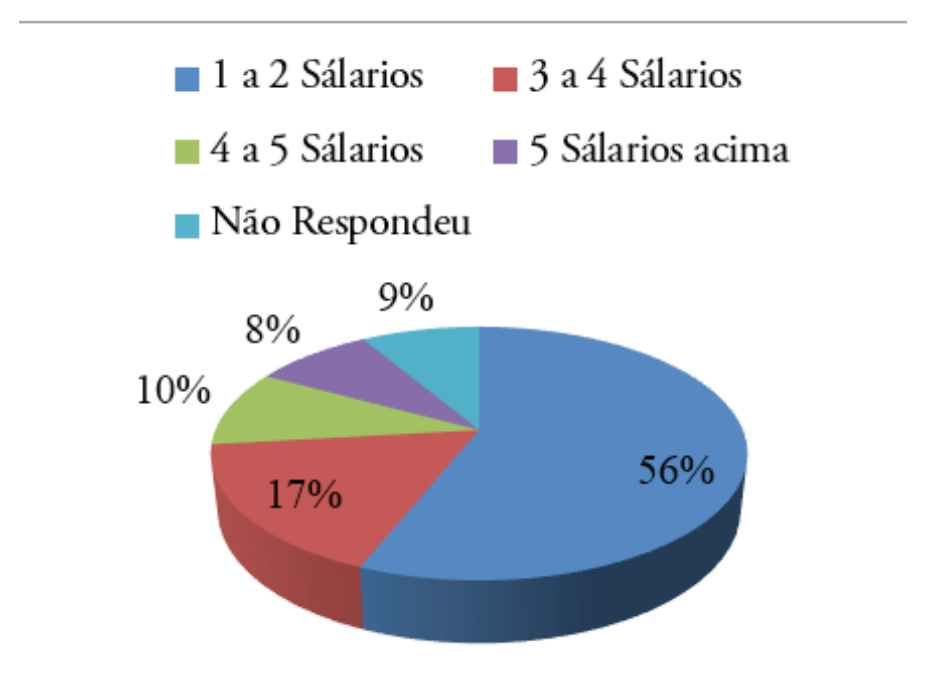


Dessa forma, podemos perceber o quão diversificadas são as salas de aula. As diferenças aparecem de forma econômica, cultural, social e de estilos de vida. A sala de aula torna-se um "caldeirão" de sujeitos, cada um com sua particularidade. É por esse fato que a multiculturalidade apontada por Araújo (2000) torna-se um elemento tão importante na elaboração do PPP. Dar importância a essa realidade no documento e estar de posse dos indicadores sociodemográficos, da situação da renda familiar e da inserção no mercado de trabalho dos alunos, bem como do andamento escolar do educando permite pensar a escola como um todo, incluindo as situações relacionadas aos problemas de ensino-aprendizagem e permitindo a articulação de estratégias para a superação desses problemas, tornando a escola um espaço de todos, de inclusão e de formação do cidadão em todos os aspectos.

Ao analisarmos o PPP da escola, conviver em seu ambiente por dois meses e conhecer a sua diversidade, podemos, com o auxilio do referencial teórico, perceber que, infelizmente, o PPP não foi construído/aplicado da maneira indicada pela teoria e pela legislação. Segundo Freitas (1991), para superar as dificuldades na elaboração do PPP, deve-se fazer uso de novas formas na elaboração da ferramenta, e essas:

\begin{abstract}
[...] têm que ser pensadas em um contexto de luta, de correlações de força - às vezes favoráveis, às vezes desfavoráveis. Terão que nascer no próprio "chão da escola", com apoio dos professores e pesquisadores. Não poderão ser inventadas por alguém, longe da escola e da luta da escola. (FREITAS, 1991, p. 23).
\end{abstract}

Apesar dos limites, os problemas da comunidade em que a instituição encontra-se são levados em consideração e a escola procura minimizá-los por meio de projetos escolares que abordam problemas sociais. Todavia, a análise do referido PPP evidenciou suas fragilidades, identificando-o como um documento de efeitos burocráticos servindo como uma ferramenta do Estado para o controle de suas instituições escolares.

\title{
Considerações finais
}

Durante a realização desta pesquisa, foi possível conhecer muitos aspectos até então vistos apenas de maneira teórica, sendo muito importante ressaltar a importância do contato com a escola pesquisada, proporcionando, assim, um pouco de entendimento do que vem a ser a realidade do sistema educacional.

O próprio sistema funciona como um mecanismo desmotivador, principalmente com relação aos incentivos recebidos pelos profissionais destinados a implantar seus projetos. Outra barreira é a ideia de que a educação é a redentora de todos os problemas sociais, passando a escola a receber cada vez mais cargas das famílias que a consideram responsável por toda educação, inclusive moral, de seus filhos. Entretanto, é muita pretensão incumbir à escola o papel de resolver, de uma só vez e sozinha, problemas que se encontram nas raízes do sistema capitalista, calcado nas bases da separação das classes, na desigualdade e descaso pelo social.

Porém, foi possível perceber pontos positivos, e um deles, que deve ser muito bem ressaltado, é a presença de educadores que ainda depositam suas esperanças nas 
mudanças que um dia poderão acontecer para melhorar o processo de ensino-aprendizagem, que se esforçam, apesar de tudo, na intenção de que se efetive um aprendizado rico em conhecimentos teóricos e do cotidiano.

O Projeto Político Pedagógico da escola pesquisada é um documento cheio de boas intenções. Porém, elas nem sempre podem ser efetivadas, visto que as condições oferecidas, principalmente por parte do Estado, são poucas. A implantação do PPP caminha a passos lentos. Fazendo nossas as palavras da coordenadora pedagógica da escola em questão: "o PPP está caminhando bem, se não aparecer outro gestor que 'bagunce' tudo outra vez, tem todas as possibilidades de dar certo”.

Por fim, mesmo diante dos problemas encontrados, defende-se que o PPP deve ser elaborado e aplicado de forma coletiva, destacando não só problemas escolares, mas também os de cunho social que estão à volta das instituições. O Projeto Político Pedagógico, em uma sociedade multicultural, é estabelecido com o fim de proporcionar a autonomia da escola, sem negar seu passado e nem a diversidade cultural, econômica, linguística, política e social dentro do próprio seio escolar. Para que a escola assuma sua função social e ao mesmo tempo enfrente desafios atuais, a educação de qualidade deve ser meta fundamental a ser atingida. Reconhece-se que esta árdua tarefa não pode ser apenas de propriade dos gestores ecolares, cabendo a participação da comunidade nos espaços de discussão coletiva, bem como dos alunos na vida escolar além do ensino. Para isso, mudanças de estrutra social devem acontecer, mudanças que podem e devem ser incentivadas no cotidiano dos estudantes pelos professores demais profissionais da educação.

\section{Referências}

ARAÚJO, A. C. Gestão democrática da educação: a posição dos docentes. 2000. 220f. Dissertação (Mestrado em Educação) - Universidade de Brasília (UnB). Brasília, 2000.

BRASIL. Lei no 9.394, de 20 de dezembro de 1996. Estabelece as diretrizes e bases da educação nacional. Diário oficial da União, Brasília (DF), 23 de dez. de 1996. Seção 1, p.1-9. Disponível em: <http://www.presidencia.gov.br/legislacao/>. Acesso em: ago. 2013.

CAVALCANTI, Lana de Souza. Bases teórico-metodológicas da Geografia: uma referêcnia para a formação e a prática de ensino. In. CAVALCANTI, Lana de Souza. A geografia escolar e a cidade: ensaios sobre o ensino de geografia para a vida urbana cotidiana. Campinas, S.P: Papirus, 2008, p. 39-62.

DOURADO, Luiz Fernandes; DUARTE, Marisa Ribeiro Teixeira. Progestão: como promover, articular e envolver a ação das pessoas no processo de gestão escolar? módulo II, Brasília: CONSED - Conselho Nacional de Secretários da Educação, 2001;

ENTREVISTADO A. Entrevista I. [Ago./Set 2013]. Entrevistadores: Hamilton Matos Cardoso Júnior; Priscilla Fabiane de Brito. Anápolis - Goiás, 2013. 1 arquivo .mp3 (55 min.).

FREITAS, Luiz Carlos. "Organização do trabalho pedagógico". Palestra proferida no VII Seminário Internacional de Alfabetização e Educação. Novo Hamburgo, agosto de 1991 (mimeo).

GADOTTI, Moacir. Projeto político-pedagógico da escola: fundamentos para a sua realização. In: GADOTTI, Moacir; ROMÃO, José Eustáquio (orgs.). Autonomia da escola: princípios e propostas. São Paulo: Cortez, 1997, p. 33-41.

GIL, Antônio Carlos. Métodos e técnicas de pesquisa social. 5. ed. São Paulo: Atlas, 1999. 
Hamilton Matos Cardoso Júnior - Priscilla Fabiane de Brito - Divina Aparecida Leonel Lunas - Thiago Weslei de Almeida Sousa

GRACINDO, Regina Vinhaes. O gestor escolar e as demandas da gestão democrática: Exigências, práticas, perfil e formação. In: Revista Retratos da Escola, Brasília, v. 3, n. 4, p. 135-147, jan./jun. 2009.

GRACINDO, Regina Vinhaes. Projeto político-pedagógico: retrato da escola em movimento. In: AGUIAR. Márcia A.; SILVA, Aída Monteiro (Org.). Retrato da Escola no Brasil. Brasília: CN-TE, 2004, p. 163-175.

LIBÂNIO, José Carlos. Democratização da escola pública: a pedagogia crítico-social dos conteúdos. 19a edição, São Paulo: Editora Loyola, 2003.

MARQUES, Mário Osório. Projeto pedagógico: A marca da escola. In: Revista Contexto e Educação. vol. . 5, n’ 18. ljuí, Unijuí, abr./jun. 1990, p. 16-28.

ROMÃO, José Eustáquio. Gestão democrática do ensino público: condição da reforma educacional brasileira. In: GADOTTI, M.; ROMÃO, José Eustáquio (Orgs). Autonomia da escola princípios e propostas. São Paulo: Cortez, 1997, p. 23-31.

VASCONCELLOS, Celso dos Santos. Planejamento: plano de ensino-aprendizagem e Projeto Educativo. São Paulo: Libertad, 1995.

VEIGA, Ilma Passos Alencastro. Inovações e Projeto Político - Pedagógico: Uma relação regulatória ou emancipatória? In: Revista Educação e Sociedade, Campinas, v. 23, n. 61, dezembro/2003, p.267-281.

VEIGA, Ilma Passos Alencastro. Projeto Político da Escola: uma construção coletiva. In: VEIGA, Ilma Passos Alencastro (Org.). Projeto Político Pedagógico da Escola: uma construção possível. 11ª ed. Campinas - SP: Papirus, 1995, p. 11-35.

Notas

${ }^{1}$ Torna-se importante salientar que quando falamos de problemas, não estamos considerando apenas aqueles encontrados internamente, mas incluindo os problemas da comunidade onde a estabelecimento se insere.

${ }^{2}$ A instituição integra a Rede Estadual de Educação do Estado de Goiás.

${ }^{3}$ A escola situa-se na região sul da cidade de Anápolis.

${ }^{4}$ Sem documentação, suas instalações não podem ser reformadas com verbas estaduais, tornando-se um problema estrutural arrastado ao longo dos anos e sem previsão de resolução.

${ }^{5}$ As dependências destinadas às práticas esportivas são precárias. Possui "quadra”, que é descoberta, e um "campo de futebol" onde os alunos ficam expostos ao sol sem poder praticar suas aulas em dias chuvosos.

${ }^{6}$ Os dados apresentados a seguir são com base no conjunto de alunos das três turmas pesquisadas que totalizam 82 discentes. ( $7^{\circ}$ ano - segunda etapa do ensino fundamental).

* Mestre em Ciências Sociais e Humanidades pela Universidade Estadual de Goiás, Anápolis, Goiás, Brasil.

** Graduada em Geografia pela Universidade Estadual de Goiás, Anápolis, Goiás, Brasil.

*** Professora doutora da Universidade Estadual de Goiás, Anápolis, Goiás, Brasil.

* Prok* Prossor da Universidade Estadual de Goiás, Anápolis, Goiás, Brasil. 
Dimensões da construção e execução do projeto político pedagógico: um estudo de caso

\section{Correspondência}

Divina Aparecida Leonel Lunas Lima - Universidade Estadual de Goiás, Unidade Universitária de Ciências Sócio-Econômicas e Humanas. Avenida Juscelino Kubitschek, Jundiaí. CEP: 75110390. Anápolis, Goiânia, Brasil.

E-mail: hjuniorgo@hotmail.com - priscillabrito_prisbrito@hotmail.com - divalunas@gmail.com - tsqi@ msn.com

Recebido em 13 de novembro de 2016

Aprovado em 24 de agosto de 2017 
